\title{
Diagnostic accuracy of spot urinary protein and albumin to creatinine ratios for detection of significant proteinuria or adverse pregnancy outcome in patients with suspected pre-eclampsia: systematic review and meta-analysis
}

\begin{abstract}
Objective To determine the diagnostic accuracy of two "spot urine" tests for significant proteinuria or adverse pregnancy outcome in pregnant women with suspected pre-eclampsia.

Design Systematic review and meta-analysis.

Data sources Searches of electronic databases 1980 to January 2011, reference list checking, hand searching of journals, and contact with experts.

Inclusion criteria Diagnostic studies, in pregnant women with hypertension, that compared the urinary spot protein to creatinine ratio or albumin to creatinine ratio with urinary protein excretion over 24 hours or adverse pregnancy outcome. Study characteristics, design, and methodological and reporting quality were objectively assessed.

Data extraction Study results relating to diagnostic accuracy were extracted and synthesised using multivariate random effects meta-analysis methods.

Results Twenty studies, testing 2978 women (pregnancies), were included. Thirteen studies examining protein to creatinine ratio for the detection of significant proteinuria were included in the multivariate analysis. Threshold values for protein to creatinine ratio ranged between 0.13 and 0.5 , with estimates of sensitivity ranging from 0.65 to 0.89 and estimates of specificity from 0.63 to 0.87 ; the area under the summary receiver operating characteristics curve was 0.69 . On average, across all studies, the optimum threshold (that optimises sensitivity and specificity combined) seems to be between 0.30 and 0.35 inclusive.
\end{abstract}

However, no threshold gave a summary estimate above $80 \%$ for both sensitivity and specificity, and considerable heterogeneity existed in diagnostic accuracy across studies at most thresholds. No studies looked at protein to creatinine ratio and adverse pregnancy outcome. For albumin to creatinine ratio, meta-analysis was not possible. Results from a single study suggested that the most predictive result, for significant proteinuria, was with the DCA 2000 quantitative analyser ( $>2 \mathrm{mg} / \mathrm{mmol}$ ) with a summary sensitivity of 0.94 ( $95 \%$ confidence interval 0.86 to 0.98$)$ and a specificity of 0.94 ( 0.87 to 0.98 ). In a single study of adverse pregnancy outcome, results for perinatal death were a sensitivity of 0.82 (0.48 to 0.98 ) and a specificity of 0.59 (0.51 to 0.67 ).

Conclusion The maternal "spot urine" estimate of protein to creatinine ratio shows promising diagnostic value for significant proteinuria in suspected pre-eclampsia. The existing evidence is not, however, sufficient to determine how protein to creatinine ratio should be used in clinical practice, owing to the heterogeneity in test accuracy and prevalence across studies. Insufficient evidence is available on the use of albumin to creatinine ratio in this area. Insufficient evidence exists for either test to predict adverse pregnancy outcome.

\section{Introduction}

Pre-eclampsia is a major cause of maternal and perinatal morbidity and mortality that complicates $2-8 \%$ of all pregnancies. ${ }^{1-4}$ It is a multisystem endothelial disease that leads to glomeruloendotheliosis, ${ }^{5}$ and in severe cases it may lead to renal impairment and failure. "Permeability" of the glomerular 
basement membrane to proteins, including albumin, is key to the diagnosis. The presence of significant proteinuria (in addition to hypertension) predisposes a pregnant woman to coagulopathy, liver disease, and stroke. Serious perinatal morbidity occurs in the form of preterm delivery (often iatrogenic) and fetal growth restriction. The diagnosis of pre-eclampsia (International Society for the Study of Hypertension in Pregnancy) is determined by the presence of elevated blood pressure combined with significant proteinuria ( $\geq 0.3 \mathrm{~g} / 24$ hours) after the 20 th week of gestation in a previously normotensive, non-proteinuric patient. ${ }^{6}$ One of the "cornerstones" of antenatal care includes a screening programme directed at the detection of pre-eclampsia with regular measurements of blood pressure and urinalysis for proteinuria (often using urinalysis dipsticks). ${ }^{7}$ The "dipstick analysis," using visual reagent strips, is quick, portable, and easy to do. However, urine samples are taken at varying times of the day. This test is complicated by relatively high false positive and false negative rates ${ }^{8-10}$ so it is almost always followed up by the "gold standard" test of 24 hour urine collection. This test is in itself not without problems. The collection is cumbersome, time consuming, inconvenient (to patients as well as hospital staff), and subject to errors such as incomplete collection leading to inaccuracies (in 13-68\% of collections). ${ }^{11}$ Delays may occur in the institution of a management plan while results are awaited, and verification of diagnosis of pre-eclampsia may not be possible if patients deliver before the urine collection is complete. The laboratory assay methods used also vary widely, and the incidence of significant proteinuria has been shown to vary depending on the assay used. ${ }^{12}$

A need therefore exists for a rapid, as well as a valid, accurate test to identify significant urinary proteinuria. This may lead to timelier decision making, which is likely to reduce patients' anxiety, shorten length of hospital stay with its associated cost savings, and "target" women with true pathology for treatment. The spot protein to creatinine ratio and albumin to creatinine ratio have been studied extensively outside pregnancy (renal impairment, diabetes, and kidney transplantation $)^{13-15}$; the first ratio has also been studied in hypertensive disorders of pregnancy. ${ }^{16}$ Relatively few studies have examined the diagnostic accuracy of albumin to creatinine ratio in pregnancy. ${ }^{16}$ Sufficient evidence from studies shows a strong association between random protein to creatinine ratio and 24 hour protein excretion, and the International Society for the Study of Hypertension in Pregnancy has accepted this test as a method for identification of significant proteinuria. ${ }^{6}$ However, a consensus has not yet been reached on the most appropriate threshold to be used in clinical practice, specifically in a population with suspected pre-eclampsia, ${ }^{16}$ or on its use in prediction of adverse outcomes for mother and baby. ${ }^{18}$

We did a systematic review of the literature and multivariate meta-analysis with the objective of determining the diagnostic accuracy of the protein to creatinine ratio and albumin to creatinine ratio compared with 24 hour urine collection for the detection of significant proteinuria in patients with suspected pre-eclampsia and to look at their ability to predict adverse outcome for mother and baby.

\section{Methods}

We did a systematic review according to a prospective protocol and in accordance with recommended methods. ${ }^{19-22}$

\section{Search strategy}

We searched the following sources from 1980 to the end of January 2011: Medline, Embase, CINAHL, the Cochrane Central Register of Systematic Reviews, the Cochrane Central Register of Controlled Trials, DARE, MEDION, SIGLE, Index of Scientific and Technical Proceedings, and Web of Science. We started the search at 1980, as both protein to creatinine ratio and albumin to creatinine ratio were not in use before this time. It consisted of keywords and MeSH terms relating to the tests under investigation combined with $\mathrm{MeSH}$ terms of "Pre-eclampsia," "Pregnancy complications," and "Pregnancy outcome." Appendix A shows the full search strategy. We examined the reference lists of all included primary and review articles to identify cited articles not captured by electronic searches. We used Reference Manager 11.0 to construct a comprehensive database of literature. We applied no language restrictions

We included studies if they fit the following criteria: population-pregnant women with suspected pre-eclampsia (hypertension with or without proteinuria); index test - urinary protein to creatinine ratio or albumin to creatinine ratio; reference standard - urinary protein excretion over 24 hours or adverse pregnancy outcome (as defined by authors of included studies); study design — diagnostic accuracy studies, observational studies, and randomised controlled trials. We excluded case series with fewer than 10 cases. We also excluded studies that evaluated the protein to creatinine ratio or albumin to creatinine ratio in women with medical conditions other than hypertension and those that used a reference test other than 24 hour collection or adverse pregnancy outcome.

\section{Study selection and data extraction procedures}

Two reviewers (RKM and MD) independently abstracted the data. They recorded characteristics of the study (authors, journal, year of publication, country, study design, objectives, type of medical centre, and period or duration of the study); characteristics of the participants (study population, method of selection, inclusion and exclusion criteria, whether consecutive cases, number of participants, number of excluded participants and reasons for exclusion, personal and medical characteristics of enrolled women, inpatients compared with outpatients, level of activity); information on how the diagnostic tests were carried out and the results (timing of protein to creatinine ratio or albumin to creatinine ratio compared with 24 hour urine collection, method of assessment for the completeness of 24 hour urine collection, number of incomplete collections, prevalence of significant proteinuria (significant $>300 \mathrm{mg} / 24$ hours, severe $>5000 \mathrm{mg} / 24$ hours), range of proteinuria, laboratory methods for measurement of protein and creatinine, and results of diagnostic test); definitions of adverse outcome for mother or baby (acceptable definitions were any reported by the authors of the included studies); and methods for assessing the diagnostic accuracy of the tests and the results (number of true positives, number of true negatives, sensitivity, specificity, positive likelihood ratio, negative likelihood ratio, method of agreement, receiver operating characteristics curve, area under the curve, and the proposed diagnostic cut-off point for significant proteinuria).

Disagreements were resolved by consensus or arbitration of a third reviewer (MDK). For multiple or duplicate publication of the same dataset, we included only the most recent or complete study. 


\section{Assessment of study quality}

At least one reviewer used validated tools to assessed all included manuscripts for study and reporting quality. ${ }^{23-25} \mathrm{We}$ defined methodological quality as the confidence that the study design, conduct, and analysis minimised biases in answering the research question, focusing on the internal validity (that is, the degree to which the results of an observation are correct for the patients being studied). Items considered important for a good quality paper were prospective design with consecutive/random recruitment or cross sectional studies, full verification of the test result with an outcome measure $(>90 \%)$, adequate description of the population and index test, and whether the clinicians managing the patients were blinded to the results of the index test. Consecutive recruitment is important to minimise bias and give a better reflection of the population. Prospective recruitment is important to ensure adequate and accurate collection of baseline variables and more complete follow-up. For the diagnosis of significant proteinuria, we also considered cross sectional studies to be of high quality as no time element is present.

We used QUADAS to assess the quality of the papers. We used the STARD checklist to assess elements of study design that were likely to have a direct relation to bias in a study of test accuracy.

\section{Data synthesis}

From the two by two tables, we calculated the following parameters for the different indices and various thresholds with their $95 \%$ confidence intervals for individual studies: sensitivity (true per cent positive), specificity (true per cent negative), and likelihood ratios (the ratio of the probability of the specific test result in people who have the disease to the probability in people who do not). Likelihood ratios indicate by how much a given test result raises or lowers the probability of the patient having the disease and have been recommended by evidence based medicine groups. ${ }^{26}{ }^{27}$ Where two by two tables contained zero cells, we added 0.5 to each cell to enable calculations. ${ }^{28} \mathrm{We}$ pooled results among groups of studies with the same threshold for protein to creatinine ratio or albumin to creatinine ratio (where necessary, we recalculated thresholds to $\mathrm{mg} / \mathrm{mg}$ to ensure consistency of units) and the same outcome measure (either significant proteinuria (significant $>300 \mathrm{mg} / 24$ hours, severe $>5000 \mathrm{mg} / 24$ hours) on 24 hour collection or adverse pregnancy outcomes).

\section{Multivariate meta-analysis for protein to creatinine ratio to detect significant proteinuria compared with 24 hour urine collection}

For many of the studies, we could extract test accuracy results for protein to creatinine ratio at multiple thresholds; for example, for Al Ragip et al, ${ }^{29}$ a two by two table expressing the number of true positives, true negatives, false positives, and false negatives was available for each of five protein to creatinine ratio thresholds $(0.13,0.18,0.19,0.2$, and 0.49$)$. Multiple test accuracy results within the same study are correlated, as the same patients are contributing their data to each of the thresholds. For example, one would expect a strong positive correlation between test accuracy results at neighbouring thresholds. This within study correlation between thresholds should be accounted for in the meta-analysis by synthesising all thresholds simultaneously, as it contains important information that is otherwise lost. ${ }^{30}$ In particular, by using the within study correlations one can "borrow strength" across thresholds $^{31}$; this means that, for example, if a study presents results for a threshold of 0.2 but not for threshold 0.3 then, with any knowledge of the within study correlation between estimates at 0.2 and 0.3 in other studies, this study can still provide some indirect information about test accuracy at threshold 0.3 .

To model thresholds simultaneously and account for their correlation, we used a three step multivariate meta-analysis approach which extends that used by Reitsma et al. ${ }^{32}$ This three step approach was as follows. Step 1: take each study separately and estimate the logit sensitivity and logit specificity at each threshold available and their associated standard errors and correlation; if zero cells existed (for example, for the number of false negatives) at any threshold, then add 0.5 to all cells for all thresholds. Step 2: use a multivariate random effects meta-analysis to jointly synthesise all the estimates simultaneously across studies while accounting for their within study and between study correlation, their within study standard errors, and between study heterogeneity, to produce summary estimates of logit sensitivity and logit specificity at each threshold and an estimate of the between study standard deviation (heterogeneity) in sensitivity and specificity (on the logit scale) at each threshold. Step 3: fit a regression model to the summary estimates of logit sensitivity and logit specificity obtained for each threshold value, to ensure that the summary results are constrained and ordered appropriately (that is, the summary sensitivity decreases as the threshold increases, and the summary specificity increases as threshold increases), while again ensuring that the uncertainty and correlation between all summary estimates are accounted for. Using the regression lines, constrained summary estimates and their confidence intervals can then be obtained for each threshold and the summary receiver operating characteristics curve plotted.

To calculate the area under the summary curve, we extrapolated it to (0.1) and (1.0) at either side and integrated it by using cubic spines in Stata statistical software release 11 via the "integ" command. We excluded one study (Skweres et $\mathrm{al}^{33}$ ) from this multivariate meta-analysis, as it had unusual results with sensitivity increasing as the threshold increased. We considered an alternative multivariate approach recommended by Hamza et al, ${ }^{34}$ but it would not converge.

\section{Results}

Figure $1 \Downarrow$ summarises the process of identification and selection of studies. Of the 3213 potential citations, we included 20 primary articles in the critical appraisal and systematic review. ${ }^{10} 29^{33} 35-51$ Appendix B details the individual characteristics of the included studies. The 20 studies reported on 2978 pregnant women and produced 88 two by two tables. Thirteen were cohort studies, four were cross sectional studies, one was a case-control study, and two were purposely designed diagnostic accuracy studies. Ten studies used prospective recruitment of patients, four stated that consecutive recruitment was used, one was retrospective, and nine studies had unclear design. Thirteen studies excluded patients with proven urinary tract infections, five excluded those with chronic hypertension, and 11 excluded patients with chronic renal disease. Four papers included only inpatients on bed rest.

For the 24 hour urine collection, five papers reported that they excluded patients with inadequate urine collections, and one paper gave specific details on the tests for this. We noted significant heterogeneity in method of protein measurement. One study used the trichloroacetic acid method, five used the Biuret reaction, five used the pyrogallol red reaction, one used the Bradford assay, two used the turbidimetric method, and one 
used benzamethonium chloride. Methods of creatinine measurement included 12 studies using the Jaffe methods, one using the two pint rate methods, and one using the iminohydrolase reaction.

\section{Quality of studies}

Figure $2 \Downarrow$ shows a summary of the quality assessment of the included studies. We found good compliance with appropriate population spectrum, selection criteria adequately described, appropriate reference standard, and adequate description of index and reference standard. Blinding of the assessors of the outcome measure to the results of the albumin to creatinine ratio or protein to creatinine ratio was poorly reported (3/20 studies). No studies reported on the use of any treatment in between the albumin to creatinine ratio or protein to creatinine ratio and delivery or whether the results of the tests were used in determining patients' management. Verification bias was minimised, as the number of eligible women progressing to the reference standard in included studies was more than $90 \%$ in $18 / 20$. Five out of the 20 included studies used less than $80 \%$ of included women in the final analysis; reasons for this included exclusion after trial entry, lack of verification with reference standard, and loss to follow-up. In 379 (13\%) cases this was due to incomplete 24 hour urine collection.

\section{Summary results for protein to creatinine ratio to detect significant proteinuria compared with 24 hour urine collection}

Fifteen studies compared protein to creatinine ratio with 24 hour urine collection (2790 women). No studies evaluated protein to creatinine ratio and adverse pregnancy outcome. Of the 15 studies using 24 hour collection as the outcome measure, 10 were in pregnant women with hypertension, four were in a population with hypertension and proteinuria on dipstick analysis, and in one the population was not clear. Thirteen of the 15 papers reported the approximate time during the day that the spot test was taken, and nine of the 15 reported the timing with respect to the 24 hour urine collection.

Tables $1 \Downarrow$ and $2 \Downarrow$ show the results for the constrained sensitivity, specificity, and likelihood ratios using the multivariate meta-analysis. Thirteen studies reported adequate data on the threshold of the reference standard for inclusion in this analysis. For sensitivity, no threshold gave a summary sensitivity estimate above $90 \%$. Threshold values between 0.31 and 0.13 gave summary estimates between $80 \%$ and $90 \%$, and the summary estimate was below $70 \%$ for thresholds of 0.45 and above. For specificity, no threshold gave a summary specificity estimate above $90 \%$, but thresholds between 0.39 and 0.50 gave summary estimates between $81 \%$ and $87 \%$. The summary specificity estimate was $70 \%$ or more for a threshold of 0.22 or above.

We found considerable heterogeneity at any threshold for which two or more studies provided evidence; for example, the between study standard deviation for sensitivity was estimated at between 0.41 and 1.58 in such studies. This heterogeneity may cause the performance of protein to creatinine ratio in an individual study setting to be somewhat different from the summary "average" results presented here (table $1 \Downarrow$ ).

Figure $3 \Downarrow$ shows the summary receiver operating characteristics curve for the constrained estimates. The area under the curve was 0.69 , which indicates a good discriminatory ability on average across studies. The question arises as to which threshold for protein to creatinine ratio gives, on average across all studies, the best summary results for sensitivity and specificity combined. No threshold gave a summary estimate above $80 \%$ for both sensitivity and specificity. Threshold values between 0.22 and 0.40 gave summary estimates above $70 \%$ for both sensitivity and specificity (table $1 \Downarrow$ ). The optimum threshold (that which maximises both sensitivity and specificity jointly) seems to be somewhere between 0.30 and 0.35 inclusive (fig $3 \Downarrow)$.

The prevalence of proteinuria varied across studies from $14 \%$ to $87 \%$ owing to the variability in severity of the included populations, so we did a subgroup analysis using only those studies that included women with hypertension and proteinuria on dipstick analysis ( $\mathrm{n}=4$ studies, 279 women). The only threshold for which we could do this analysis was a protein to creatinine ratio above 0.2 ( $n=3$ studies, 237 women). The results were sensitivity 0.86 (95\% confidence interval 0.79 to 0.91 ), specificity 0.95 ( 0.89 to 0.98$)$, positive likelihood ratio 14.11 (6.29 to 31.67), and negative likelihood ratio 0.13 (0.06 to 0.29 ). To determine the predicted probability of disease given a positive test result and also the predicted probability of non-disease given a negative test result, we considered a range of different prevalences $(0.2,0.5$, and 0.8$)$ and combined each with the summary sensitivity and specificity estimates from our meta-analysis. The results in appendices C-E show that the predicted values clearly depend on the cut-off value chosen and the prevalence assumed. Higher prevalences lead to higher estimates of positive predictive value and lower estimates of negative predictive value, and vice versa. These values are based on using the average sensitivity and specificity from the meta-analysis, but these also vary across settings.

\section{Albumin to creatinine ratio}

For albumin to creatinine ratio, we had five included studies (620 women). Four studies used 24 hour total protein as the reference standard and one used adverse pregnancy outcome. Of the four studies that used 24 hour collection as the reference standard, two were in a hypertensive population and two were in a population with hypertension and proteinuria on dipstick. The study using adverse pregnancy outcome was in a population with hypertension only. Three studies described the timing of the sample, and one described the relation of the timing of the 24 hour collection. Three papers reported the use of automatic dipstick analysers for albumin to creatinine ratio.

\section{Summary results for albumin to creatinine ratio to detect significant proteinuria compared with 24 hour urine collection}

Meta-analysis of results from studies of albumin to creatinine ratio was not possible owing to different thresholds and study characteristics. Table $3 \Downarrow$ shows the results for the individual studies. The most promising result was with the DCA 2000 quantitative analyser $(>2 \mathrm{mg} / \mathrm{mmol})$ with sensitivity $0.94(0.86$ to 0.98 ), specificity 0.94 ( 0.87 to 0.98$)$, positive likelihood ratio 14.65 (6.74 to 31.84 ), and negative likelihood ratio 0.07 (0.03 to 0.16$)$.

\section{Summary results for albumin to creatinine ratio to predict adverse outcome}

One study (Gangaram et $\mathrm{al}^{39}$ ) reported results for adverse outcome, including maternal morbidity, for which the sensitivity was 0.55 (0.23 to 0.83 ) and specificity was 0.57 (0.48 to 0.65$)$, and perinatal death, for which the sensitivity was 0.82 ( 0.48 to 0.98 ) and specificity was 0.59 (0.51 to 0.67 ). 


\section{Discussion}

The main findings of our systematic review were that, on average across all studies, the optimum threshold (to maximise sensitivity and specificity) for protein to creatinine ratio to detect significant proteinuria is between 0.30 and 0.35 , relating to sensitivity and specificity values above $75 \%$. However, no threshold gave a summary estimate above $80 \%$ for both sensitivity and specificity, and considerable heterogeneity existed in diagnostic accuracy across studies at most thresholds. Thus, although the protein to creatinine ratio shows promising diagnostic value, how it should be implemented in clinical practice is unclear from the evidence. For albumin to creatinine ratio, meta-analysis was not possible; the results are based on single studies and show that albumin to creatinine ratio shows potential to be a good diagnostic test. No studies assessed protein to creatinine ratio to predict adverse pregnancy outcome, and only one study assessed this for albumin to creatinine ratio, so insufficient evidence exists for us to comment on the use of these tests in this context.

The finding of "significant proteinuria" is key to the diagnosis of pre-eclampsia, stratification of perinatal risk, and hence the management of pregnant women with hypertension. Women with significant proteinuria are at increased risk of maternal and perinatal morbidity and mortality. ${ }^{52}$ Accurate diagnosis and thus diagnostic tests are important to limit inappropriate intervention in the form of further testing or treatment. In the United Kingdom, the standard testing is for women to have a 24 hour urine collection for total protein estimation as either an outpatient or an inpatient, which is inconvenient for the women, has cost implications, can imply a delay in diagnosis and implementation of treatment, and has weaknesses resulting from incomplete collection and varying use of assays leading to inconsistent test results. A need thus exists for a quick, reliable, acceptable, and cost effective alternative. This systematic review evaluated spot protein to creatinine ratio and albumin to creatinine ratio in the management of pregnant women with suspected pre-eclampsia.

\section{Strengths and limitations}

The strengths of our review lie in the methods adhering to recent guidelines for diagnostic reviews, ${ }^{19212253}$ as well as in the advanced statistical methods used, ${ }^{30}{ }^{32}$ which analyse all reported thresholds simultaneously and account for all their correlated results. Our searches were extensive and continually updated during the review. We made no exclusions on the basis of language. As with any systematic review, the analyses that are possible and the inferences that can be made from the data are always limited by the quality of the primary research. Although many of the papers included in this review had adhered to many of the guidelines for reporting and methodological quality of diagnostic accuracy studies, ${ }^{23}{ }^{25}$ significant limitations still existed in the description of blinding and use of any treatment in between the index test and reference standard. The details of the index test, reference test, and population characteristics were deemed to be adequately reported, but considerable variation existed in these study characteristics, rendering subgroup analysis in these areas impossible.

Although 24 hour urine collection for total protein is still used as the gold standard for comparison of tests for proteinuria, this test itself has many limitations, as discussed in the introduction-namely, that it is time consuming, inconvenient, and subject to errors such as incomplete collection.

This comparison of tests also has little bearing on actual outcomes of pregnancy. This is a limitation of the studies in our review and thus a limitation of our meta-analyses. Once pre-eclampsia is diagnosed, the treatment options that may be instituted are to manage and limit the complications of pre-eclampsia, and the only cure is delivery of the placenta. One aim of this review was to investigate the ability of spot protein to creatinine ratio and albumin to creatinine ratio to predict adverse outcomes of pregnancy. The fact that only one paper used this as an outcome measure, and that this was for albumin to creatinine ratio, was disappointing.

\section{Comparison with other studies}

One review has previously been published in this area. ${ }^{16}$ This review concluded that protein to creatinine ratio was a reasonable "rule out" test for detecting significant proteinuria in hypertensive pregnancy. However, this review included women with all types of hypertension in pregnancy (that is, not those with suspected pre-eclampsia). The review by Côté et al calculated new results from the individual studies for the presumed ideal cut-off value of $30 \mathrm{mg}$ protein $/ \mathrm{mmol}$ creatinine. However, we did not decide in advance which threshold is best and rather considered results at all reported thresholds and jointly meta-analysed them to assess how the summary sensitivity and specificity change according to the threshold chosen. Furthermore, our multivariate meta-analysis accounts for the correlation within and across studies due to the thresholds and produces a summary receiver operating characteristics curve in which summary results for each threshold are easily identifiable (fig $3 \Downarrow$ ). Thus, although our conclusions are consistent with the optimum threshold being around 0.3 , our results are more robust owing to the use of more reported information, in combination with more stringent inclusion criteria, inclusion of more studies, and more recent studies (after 2007) that are thus more likely to adhere to quality guidelines. We also evaluated adverse pregnancy outcome as a comparator for the albumin to creatinine ratio and protein to creatinine ratio, although as already stated this could not be properly assessed owing to the small number of studies.

\section{Clinical application}

When considering the most appropriate diagnostic threshold for a test in practice, one must consider the trade-off between sensitivity and specificity that relates to threshold. What is acceptable in clinical practice will be determined by the place of the test in the management pathway (such as add-on, triage, or replacement) and the nature of the disease. ${ }^{54}$ When considering pre-eclampsia, one would wish a replacement test (stand alone) to limit the number of false negative results, as these women run the risk of developing undetected pre-eclampsia with a risk of serious morbidity and mortality. Women with false positive results will be subjected to increased monitoring and possibly pre-term delivery. Thus, protein to creatinine ratio as a replacement test would ideally use a threshold that maximises sensitivity and specificity. If protein to creatinine ratio were to be used as a triage test, with patients who test positive going on to have a 24 hour urine collection to verify the significant proteinuria, then false negatives need to be minimised but false positives will be identified by the second test, so sensitivity can be maximised at the expense of specificity. Our results can be used to determine the most appropriate threshold for each of these situations.

The findings from the multivariate meta-analysis relate to the accuracy of protein to creatinine ratio at the summary level (that is, averaged across all studies). Considerable heterogeneity exists at any threshold for which two or more studies provide evidence, so the performance of protein to creatinine ratio in an 
individual study setting may be somewhat different from the summary results presented here. Further research needs to identify the causes of heterogeneity in test accuracy across studies (for example, method of measurement, inaccurate reference standards) and identify those circumstances in which protein to creatinine ratio performs consistently well.

Prevalence of proteinuria also varied considerably across studies and has a big effect on how a protein to creatinine ratio test could be used. Following the protein to creatinine test, high positive and negative predictive values above 0.85 are achieved when the prevalence is high (for example, 0.8 ; see appendix E). However, when the prevalence is low (for example, 0.2; see appendix $\mathrm{C}$ ), the negative predictive value remains above 0.85 but positive predictive value is then around 0.4 . Thus a negative protein to creatinine ratio remains a good test for ruling out significant proteinuria, but positive tests results may have a high rate of false positives in this low prevalence population. Clinicians thus need to know the prevalence of significant proteinuria in the population and setting under investigation to allow accurate interpretation of the test results

\section{Conclusions}

The available evidence suggests that the protein to creatinine ratio has promising diagnostic value for significant proteinuria in suspected pre-eclampsia. The existing evidence is not, however, sufficient to determine how protein to creatinine ratio should be used in clinical practice, as it compares protein to creatinine ratio only with the presumed gold standard of 24 hour urine collection, and large heterogeneity exists in diagnostic accuracy across studies, even at the same threshold. Before its widespread implementation, the most appropriate setting, the prevalence of proteinuria in that setting, the most appropriate cut-off value to limit maternal and fetal morbidity and mortality, and the further testing and interventions that should follow a positive or negative test result need to be determined, and evidence for its cost effectiveness is needed. This evidence can be obtained only by prospectively designed studies of test accuracy with adequate sample size and attention to limiting bias and using appropriate outcome measures and cost effectiveness analysis using a decision tree model. ${ }^{5566}$ This will allow the trade-off between positive and negative benefits to be truly evaluated.

Contributors: All authors were responsible for the design of the study. RKM, MD, and MDK were responsible for the data extraction and RKM, $\mathrm{RR}$, and JD for the analysis. All authors checked the analysis and were involved in the drafting and critical revision of the manuscript. MDK is the guarantor.

Funding: RKM is funded by a National Institute for Health Research clinical lectureship. RR and JD are supported by funding from the Medical Research Council Hub for Trials Methodology Research at the University of Birmingham (MRC grant ID G0800808).

Competing interests: All authors have completed the Unified Competing Interest form at www.icmje.org/coi_disclosure.pdf (available on request from the corresponding author) and declare: no support from any organisation for the submitted work; no financial relationships with any organisations that might have an interest in the submitted work in the previous three years; no other relationships or activities that could appear to have influenced the submitted work.

Ethical approval: Not required.

Data sharing: Technical appendix, statistical code, and dataset available from corresponding author at m.d.kilby@bham.ac.uk. Consent was not obtained, but the presented data are anonymised and risk of identification is low.
1 Confidential Enquiry into Maternal and Child Health (CEMACH). Saving mothers' lives: reviewing maternal deaths to make motherhood safer-2003-2005. The seventh report on confidential enquiries into maternal deaths in the United Kingdom. CEMACH, 2005.

2 Montan S, Sjoberg N, Svenningsen N. Hypertension in pregnancy-fetal and infant outcome: a cohort study. Hypertens Pregnancy 1987;6:337-48.

3 Khan K, Wojdyla D, Say L, Gulmezoglu A, Van Look PF. WHO analysis of causes of maternal death: a systematic review. Lancet 2006;367:1066-74.

4 World Health Organization. WHO international collaborative study of hypertensive disorders of pregnancy: geographic variation in the incidence of hypertension in pregnancy. $A m J$ Obstet Gynecol 1988;158:80-3.

5 Hennessy A, Makris A. Preeclamptic nephropathy. Nephrology 2011;16:134-43.

6 Brown MA, Lindheimer MN, De Swiet M, Van Assche A, Moutquin JM. The classification and diagnosis of the hypertensive disorders of pregnancy: statement from the International Society for the Study of Hypertension in Pregnancy (ISSHP). Hypertens Pregnancy 2001;20:ix-xiv.

7 National Institute for Health and Clinical Excellence. Antenatal care: routine care for the healthy pregnant woman. (NICE clinical guideline 62.) NICE, 2008.

8 Kuo VS, Koumanantakis G, Gallery EDM. Proteinuria and its assessment in normal and hypertensive pregnancy. Am J Obst Gynecol 1992;167:723-8.

9 Meyer NL, Mercer BM, Friedman SA, Sibai BM. Urinary dipstick protein: a poor predictor of absent or severe proteinuria. Am J Obst Gynecol 1994;170:137-41.

10 Waugh JJS, Bell SC, Kilby MD, Blackwell CN, Seed P, Shennan AH, et al. Optimal bedside analysis for the detection of proteinuria in hypertensive pregnancy: a study of diagnostic accuracy. Br J Obstet Gynaecol 2005;112:412-7.

11 Côté AM, Firoz T, Mattman A, Lam EM, von Dadelszen P, Magee LA. The 24 hour urine collection: gold standard or historical practice? Am J Obst Gynecol 2008;199:e1-6.

12 Waugh J, Bell SC, Kilby MD, Lambert P, Shennan AH, Halligan AWF. Urine protein estimation in hypertensive pregnancy: which thresholds and laboratory assay best predict clinical outcome? Hypertens Pregnancy 2005;24:291-302.

13 Ginsberg JM, Chang BS, Matarese RA, Garella S. Use of single voided urine samples to estimate quantitative proteinuria. N Engl J Med 1983;309:1543-6.

14 Steinhauslin F, Wauters JP. Quantitation of proteinuria in kidney transplant patients: accuracy of the protein/creatinine ratio. Clin Nephrol 1995;43:110-5.

15 Brodby RA, Rohde RD, Zeev S, Pohl MA, Bain RP, Lewis EJ. The urine protein to creatinine ratio as a predictor of 24 hour urine protein excretion in type 1 diabetic patients with nephropathy. Am J Kidney Dis 1995;26:904-9.

16 Côté AM, Brown MA, Lam EM, von Dadelszen P, Firoz T, Liston RM, et al. Diagnostic accuracy of urinary spot protein:creatinine ratio for proteinuria in hypertensive pregnant women: systematic review. BMJ 2008;336:1003-6.

17 Papanna R, Mann LK, Koiudes RW, Glantz JC. Protein/creatinine ratio in preeclampsia: systematic review. Obstet Gynecol 2008;112:135-44.

18 Thangaratinam S, Commarasamy A, O'Mahony F, Sharp S, Zamora J, Khan K, et al. Estimation of proteinuria as a predictor of complications of pre-eclampsia: a systematic review. BMC Med 2009;7:10.

19 Irwig L, Tosteson AN, Gatsonis C, Lau J, Colditz G, Chalmers TC, et al. Guidelines for meta-analyses evaluating diagnostic tests. Ann Intern Med 1994;120:667-76.

20 Deeks J. Systematic reviews in health care: systematic reviews of diagnostic and screening tests. BMJ 2001;323:157-62.

21 Khan KS, Dinnes J, Kleijnen J. Systematic reviews to evaluate diagnostic tests. Eur J Obstet Gynecol Reprod Biol 2001;95:6-11.

22 Cochrane Collaboration. Handbook for DTA reviews. 2011. http://srdta.cochrane.org/ handbook-dta-reviews.

23 Whiting P, Rutjes AW, Reitsma JB, Bossuyt PM, Kleijnen J. The development of QUADAS a tool for the quality assessment of studies of diagnostic accuracy included in systematic reviews. BMC Med Res Methodol 2003;3:25.

24 Whiting PF, Weswood ME, Rutjes AW, Reitsma JB, Bossuyt PN, Kleijnen J. Evaluation of QUADAS, a tool for the quality assessment of diagnostic accuracy studies. BMC Med Res Methodol 2006;6:9.

25 Bossuyt PM, Reitsma JB, Bruns DE, Gatsonis CA, Glasziou PP, Irwig LM, et al. Towards complete and accurate reporting of studies of diagnostic accuracy: the STARD initiative. Ann Intern Med 2003;138:40-4.

26 Honest $\mathrm{H}, \mathrm{Khan} \mathrm{KS}$. Reporting of measures of accuracy in systematic reviews of diagnostic literature. BMC Health Serv Res 2002:2:4.

27 Jaeschke R, Guyatt GH, Sackett DL. Users' guides to the medical literature. III. How to use an article about a diagnostic test. B. What are the results and will they help me in caring for my patients? JAMA 1994;271:703-7.

28 Sankey S, Weistfiels L, Fine M, Kapoor W. An assessment of the use of the continuity correction for sparse data in meta analysis. Commun Stat Simulation Computation 1996;25:1031-56.

29 Al RA, Baykal C, Karacay O, Geyik PO, Altun S, Dolen I. Random urine protein-creatinine ratio to predict proteinuria in new-onset mild hypertension in late pregnancy. Obstet Gynecol 2004;104:367-71.

30 Riley RD. Multivariate meta-analysis: the effect of ignoring within-study correlation. JRSS Series A 2009;172:789-811.

31 Riley RD, Abrams KR, Lambert PC, Sutton A.J, Thompson JR. An evaluation of bivariate random-effects meta-analysis for the joint synthesis of two correlated outcomes. Stat Med 2007;26:78-97.

32 Reitsma JB, Glas AS, Rutjes AW, Scholten RJ, Bossuyt PM, Zwinderman AH. Bivariate analysis of sensitivity and specificity produces informative summary measures in diagnostic reviews. J Clin Epidemiol 2005;58:982-90.

33 Skweres T, Preis K, Ciepluch R, Miskiewicz K. [The value of a urine protein-to-creatinine ratio assessment in a single voided urine specimen in prediction of 24-hour proteinuria in pregnancy induced hypertension] [Polish]. Ginekologia Polska 2006;77:415-21.

34 Hamza TH, Arends LR, van Houwelingen HC, Stijnen T. Multivariate random effects meta-analysis of diagnostic tests with mutliple thresholds. BMC Med Res Methodol 2009;9:73.

35 Al RA, Borekci B, Yapca O, Keles S, Kadanali S. Albumin/creatinine ratio for prediction of 24-hour albumin excretion of $>$ or $=2 \mathrm{~g}$ in manifest preeclampsia. Clin Exp Obstet Gynecol 2009;3:169-72.

36 Aggarwal N, Suri V, Soni S, Chopra V, Kohli HS. A prospective comparison of random urine protein-creatinine ratio vs 24 -hour urine protein in women with preeclampsia. Medscape J Med 2008;10:98

37 Durnwald C, Mercer B. A prospective comparison of total protein/creatinine ratio versus 24-hour urine protein in women with suspected preeclampsia. Am J Obstet Gynecol 2003;189:848-52. 


\section{What is already known on this topic}

Spot protein to creatinine ratio has been shown to correlate well with 24 hour urinary protein estimation

A cut-off value of $30 \mathrm{mg} / \mathrm{mmol}(0.27)$ has been suggested as a reasonable "rule-out test" for proteinuria above $0.3 \mathrm{~g} /$ day

\section{What this study adds}

The optimum threshold for the spot protein to creatinine ratio to detect proteinuria $>0.3 \mathrm{~g} /$ day is between 0.30 and 0.35 , giving summary sensitivity and specificity values above 0.75

Insufficient evidence exists for determination of how protein to creatinine ratio should be used in clinical practice, owing to large heterogeneity in diagnostic accuracy and prevalence across studies

Insufficient evidence exists regarding the test accuracy of the albumin to creatinine ratio in pregnancy

38 Dwyer BK, Gorman M, Carroll IR, Druzin M. Urinalysis vs urine protein-creatinine ratio to predict significant proteinuria in pregnancy. J Perinatol 2008;28:461-7.

39 Gangaram R, Naicker M, Moodley J. Accuracy of the spot urinary microalbumin:creatinine ratio and visual dipsticks in hypertensive pregnant women. Eur J Obstet Gynecol Reprod Biol 2009;144:146-8.

40 Gangaram R, Naicker M, Moodley J. Comparison of pregnancy outcomes in women with hypertensive disorders of pregnancy using 24-hour urinary protein and urinary microalbumin to creatinine ratio. Int J Gynecol Obstet 2009;107:19-22.

41 Leanos-Miranda A, Marquez-Acosta J, Romero-Arauz F, Cardenas-Mondragon GM, Rivera-Leanos $\mathrm{R}$, Isordia-Salas I, et al. Protein:creatinine ratio in random urine samples is a reliable marker of increased 24-hour protein excretion in hospitalized women with hypertensive disorders of pregnancy. Clin Chem 2007;53:1623-8.

42 Nisell $\mathrm{H}$, Trygg M, Back R. Urine albumin/creatinine ratio for the assessment of albuminuria in pregnancy hypertension. Acta Obstet Gynecol Scand 2006;85:1327-30.

43 Ramos JG, Martins-Costa SH, Mathias MM, Guerin YL, Barros EG. Urinary protein/creatinine ratio in hypertensive pregnant women. Hypertens Pregnancy 1999;18:209-18.

44 Robert M, Sepandj F, Liston RM, Dooley KC. Random protein-creatinine ratio for the quantitation of proteinuria in pregnancy. Obstet Gynecol 1997;90:893-5.

45 Rodriguez-Thompson D, Lieberman ES. Use of a random urinary protein-to-creatinine ratio for the diagnosis of significant proteinuria during pregnancy. Am J Obstet Gynecol 2001;185:808-11.

46 Saudan PJ, Brown MA, Farrell T, Shaw L. Improved methods of assessing proteinuria in hypertensive pregnancy. Br J Obstet Gynaecol 1997;104:1159-64.

47 Schubert FP, Abernathy MP. Alternate evaluations of proteinuria in the gravid hypertensive patient. J Reprod Med 2006;51:709-14.

48 Shahbazian N, Hosseini-Asl F. A comparison of spot urine protein-creatinine ratio with 24-hour urine protein excretion in women with preeclampsia. Iran J Kidney Dis 2008;2:127-31.
49 Taherian AA, Dehbashi S, Baghban M. The relationship between random urinary protein-to-creatinine ratio and 24-hours urine protein in diagnosis of proteinuria in mild preeclampsia. J Res Med Sci 2006;11:6-12.

50 Wheeler TL, Blackhurst DW, Dellinger EH, Ramsey PS. Usage of spot urine protein to creatinine ratios in the evaluation of preeclampsia. Am J Obstet Gynecol 2007;196:465

51 Yamasmit W, Chaithongwongwatthana S, Charoenvidhya D, Uerpairojkit B, Tolosa J. Random urinary protein-to-creatinine ratio for prediction of significant proteinuria in women with preeclampsia. J Matern Fetal Neonatal Med 2004;16:275-9.

52 Freidman EA, Neff RK. Pregnancy outcomes as related to hypertension, edema and proteinuria. In: Lindheimer MD, Katz AL, Zuspan F, eds. Hypertension in pregnancy. Wiley and Sons, 1976:13-22.

53 Deeks J, Morris J. Evaluating diagnostic tests. Baillieres Clin Obstet Gynaecol 1996;10:613-30.

54 Bossuyt PM, Irwig L, Craig J, Glasziou PP. Comparative accuracy: assessing new tests against diagnostic pathways. BMJ 2006;332:1089-92.

55 Bachmann LM, Rama K, ter Riet G, Bossuyt PM. Sample sizes of studies on diagnostic accuracy: literature survey. BMJ 2006;332:1127-9.

56 Irwig L, Bossuyt PM, Glasziou PP, Gatsonis C, Lijmer JG. Designing studies to ensure that estimates of test accuracy are transferrable. BMJ 2002;324:669-71.

Accepted: 06 June 2012

\section{Cite this as: BMJ 2012;345:e4342}

This is an open-access article distributed under the terms of the Creative Commons Attribution Non-commercial License, which permits use, distribution, and reproduction in any medium, provided the original work is properly cited, the use is non commercial and is otherwise in compliance with the license. See: http://creativecommons.org/licenses/by$\mathrm{nc} / 2.0 /$ and http://creativecommons.org/licenses/by-nc/2.0/legalcode. 


\section{Tables}

Table 1/ Constrained summary sensitivity and specificity of protein to creatinine ratio

\begin{tabular}{|c|c|c|c|c|c|}
\hline Threshold & $\begin{array}{c}\text { No of studies directly } \\
\text { providing this } \\
\text { threshold }\end{array}$ & Summary sensitivity $(95 \% \mathrm{Cl})$ & $\begin{array}{l}\text { Between study standard } \\
\text { deviation }(\tau)\end{array}$ & Summary specificity $(95 \% \mathrm{Cl})$ & $\begin{array}{c}\text { Between study standard } \\
\text { deviation }(\tau)\end{array}$ \\
\hline 0.13 & 1 & $0.89(0.86$ to 0.93$)$ & 0.001 & $0.63(0.58$ to 0.68$)$ & 0 \\
\hline 0.14 & 2 & 0.89 (0.85 to 0.92$)$ & 1.23 & 0.64 (0.58 to 0.68$)$ & 0.79 \\
\hline 0.15 & 6 & 0.88 (0.85 to 0.92$)$ & 1.13 & 0.64 (0.59 to 0.69$)$ & 1.26 \\
\hline 0.16 & 3 & 0.88 (0.85 to 0.91$)$ & 1.35 & $0.65(0.60$ to 0.70$)$ & 1.5 \\
\hline 0.17 & 3 & $0.88(0.84$ to 0.91$)$ & 1.02 & $0.66(0.61$ to 0.70$)$ & 1.25 \\
\hline 0.18 & 3 & 0.88 (0.84 to 0.91$)$ & 0.84 & 0.67 (0.62 to 0.71$)$ & 1.75 \\
\hline 0.19 & 4 & $0.87(0.83$ to 0.90$)$ & 1.18 & $0.68(0.63$ to 0.72$)$ & 0.55 \\
\hline 0.20 & 7 & $0.87(0.83$ to 0.90$)$ & 0.87 & 0.68 (0.64 to 0.73$)$ & 1.68 \\
\hline 0.21 & 3 & $0.86(0.82$ to 0.89$)$ & 1.53 & 0.69 (0.65 to 0.73$)$ & 0.67 \\
\hline 0.22 & 1 & $0.86(0.82$ to 0.89$)$ & 0.005 & $0.70(0.65$ to 0.74$)$ & 0.001 \\
\hline 0.23 & 1 & 0.85 (0.81 to 0.88$)$ & 0.004 & $0.71(0.66$ to 0.75$)$ & 0.002 \\
\hline 0.24 & 2 & 0.85 (0.81 to 0.88$)$ & 1.2 & $0.71(0.67$ to 0.75$)$ & 0.74 \\
\hline 0.25 & 3 & $0.84(0.80$ to 0.87$)$ & 0.98 & $0.72(0.68$ to 0.76$)$ & 0.93 \\
\hline 0.28 & 2 & 0.82 (0.78 to 0.86$)$ & 1.21 & $0.74(0.70$ to 0.78$)$ & 0.82 \\
\hline 0.30 & 5 & $0.81(0.77$ to 0.85$)$ & 1.58 & $0.76(0.71$ to 0.80$)$ & 2.13 \\
\hline 0.31 & 1 & $0.81(0.76$ to 0.84$)$ & 0.003 & $0.76(0.72$ to 0.80$)$ & 0.003 \\
\hline 0.32 & 1 & $0.80(0.76$ to 0.84$)$ & 0.003 & $0.77(0.73$ to 0.81$)$ & 0.003 \\
\hline 0.35 & 1 & 0.78 (0.73 to 0.82$)$ & 0.002 & $0.79(0.75$ to 0.83$)$ & 0.003 \\
\hline 0.39 & 2 & $0.75(0.70$ to 0.79$)$ & 0.85 & 0.81 (0.77 to 0.85$)$ & 1.18 \\
\hline 0.40 & 2 & 0.74 (0.69 to 0.78$)$ & 0.42 & $0.82(0.78$ to 0.86$)$ & 1.27 \\
\hline 0.45 & 1 & $0.70(0.64$ to 0.75$)$ & 0.001 & $0.84(0.80$ to 0.88$)$ & 0.004 \\
\hline 0.49 & 1 & 0.66 (0.60 to 0.72$)$ & 0.01 & $0.86(0.82$ to 0.90$)$ & 0.001 \\
\hline 0.50 & 2 & 0.65 (0.59 to 0.72 ) & 0.65 & 0.87 (0.82 to 0.90$)$ & 0.76 \\
\hline
\end{tabular}


Table 2| Constrained summary likelihood ratios of protein to creatinine ratio

Threshold No of studies directly providing this threshold Summary positive likelihood ratio $(95 \% \mathrm{Cl})$ Summary negative likelihood ratio $(95 \% \mathrm{Cl})$

\begin{tabular}{llll}
0.13 & 1 & $2.38(2.00$ to 2.83$)$ & $0.17(0.11$ to 0.25$)$ \\
\hline 0.14 & 2 & $2.43(2.04$ to 2.88$)$ & $0.17(0.12$ to 0.25$)$ \\
\hline 0.15 & 6 & $2.47(2.08$ to 2.94$)$ & $0.18(0.12$ to 0.26$)$ \\
\hline 0.16 & 3 & $2.52(2.12$ to 3.00$)$ & $0.18(0.12$ to 0.26$)$ \\
\hline 0.17 & 3 & $2.57(2.15$ to 3.06$)$ & $0.18(0.13$ to 0.26$)$ \\
\hline 0.18 & 3 & $2.62(2.19$ to 3.13$)$ & $0.19(0.13$ to 0.27$)$ \\
\hline 0.19 & 4 & $2.67(2.23$ to 3.19$)$ & $0.19(0.14$ to 0.27$)$ \\
\hline 0.21 & 7 & $2.73(2.27$ to 3.26$)$ & $0.20(0.14$ to 0.27$)$ \\
\hline 0.22 & 3 & $2.78(2.31$ to 3.33$)$ & $0.20(0.15$ to 0.28$)$ \\
\hline 0.23 & 1 & $2.84(2.35$ to 3.41$)$ & $0.21(0.15$ to 0.28$)$ \\
\hline 0.24 & 1 & $2.89(2.40$ to 3.49$)$ & $0.21(0.16$ to 0.29$)$ \\
\hline 0.25 & 2 & $2.95(2.44$ to 3.57$)$ & $0.22(0.16$ to 0.29$)$ \\
\hline 0.28 & 3 & $3.01(2.48$ to 3.65$)$ & $0.22(0.17$ to 0.30$)$ \\
\hline 0.3 & 2 & $3.20(2.60$ to 3.92$)$ & $0.24(0.18$ to 0.31$)$ \\
\hline 0.31 & 5 & $3.33(2.68$ to 4.12$)$ & $0.25(0.19$ to 0.33$)$ \\
\hline 0.32 & 1 & $3.40(2.73$ to 4.23$)$ & $0.26(0.20$ to 0.33$)$ \\
\hline 0.35 & 1 & $3.47(2.77$ to 4.34$)$ & $0.26(0.20$ to 0.34$)$ \\
\hline 0.39 & 1 & $3.68(2.88$ to 4.69$)$ & $0.28(0.22$ to 0.36$)$ \\
\hline 0.4 & 2 & $3.98(3.03$ to 5.23$)$ & $0.31(0.25$ to 0.39$)$ \\
\hline 0.45 & 2 & $4.06(3.07$ to 5.37$)$ & $0.32(0.25$ to 0.40$)$ \\
\hline 0.49 & 1 & $4.47(3.22$ to 6.19$)$ & $0.36(0.28$ to 0.45$)$ \\
\hline 0.5 & 1 & $4.81(3.32$ to 6.95$)$ & $0.39(0.31$ to 0.49$)$ \\
\hline & 2 & $4.90(3.34$ to 7.15$)$ & $0.40(0.32$ to 0.50$)$ \\
\hline
\end{tabular}


Table 3| Summary of results of studies using albumin to creatinine ratio (ACR) in management of women with suspected pre-eclampsia

\begin{tabular}{|c|c|c|c|c|c|c|c|c|}
\hline $\begin{array}{l}\text { Author } \\
\text { (year) }\end{array}$ & $\begin{array}{l}\text { Population } \\
\text { characteristics }\end{array}$ & $\begin{array}{c}\text { No of } \\
\text { women }\end{array}$ & Threshold ACR & Reference test & $\begin{array}{l}\text { Sensitivity }(95 \% \\
\text { Cl) }\end{array}$ & $\begin{array}{l}\text { Specificity }(95 \% \\
\mathrm{Cl})\end{array}$ & $\begin{array}{l}\text { Positive likelihood } \\
\text { ratio }(95 \% \mathrm{Cl})\end{array}$ & $\begin{array}{l}\text { Negative likelihood } \\
\text { ratio }(95 \% \mathrm{Cl})\end{array}$ \\
\hline $\begin{array}{l}\text { Al Ragip } \\
\text { (2009) }\end{array}$ & $\begin{array}{l}\text { Hypertension } \\
\text { and proteinuria }\end{array}$ & 77 & $0.37 \mathrm{mg} / \mathrm{dL}$ & $\begin{array}{l}\geq 2 \mathrm{~g} \text { albuminuria on } \\
24 \text { hour collection }\end{array}$ & $0.33(0.15$ to 0.57$)$ & 0.18 (0.09 to 0.32$)$ & 0.41 (0.22 to 0.76$)$ & 3.63 (1.87 to 7.05$)$ \\
\hline $\begin{array}{l}\text { Gangaram } \\
(2009)\end{array}$ & $\begin{array}{l}\text { Hypertension } \\
\text { after } 20 \text { weeks }\end{array}$ & 163 & $\begin{array}{c}\geq 300 \text { mg/g } \\
\text { (Clinitek 50) }\end{array}$ & $\begin{array}{c}24 \text { hour urine }(>0.3 \\
\text { g/24 hours) }\end{array}$ & 0.63 (0.52 to 0.73$)$ & $0.81(0.70$ to 0.90$)$ & 3.33 (1.99 to 5.57$)$ & $0.46(0.35$ to 0.61$)$ \\
\hline \multirow{4}{*}{$\begin{array}{l}\text { Gangaram } \\
(2009)\end{array}$} & \multirow{4}{*}{$\begin{array}{l}\text { Hypertension } \\
\text { after } 20 \text { weeks }\end{array}$} & \multirow[t]{4}{*}{155} & \multirow[t]{4}{*}{$\geq 300 \mathrm{mg} / \mathrm{g}$} & Caesarean section & $0.45(0.34$ to 0.56$)$ & $0.59(0.46$ to 0.71$)$ & 1.09 (0.76 to 1.57$)$ & 0.94 (0.71 to 1.23$)$ \\
\hline & & & & $\begin{array}{c}\text { Maternal morbidity } \\
\text { (abruption, } \\
\text { eclampsia, } \\
\text { admission to HDU) }\end{array}$ & 0.55 (0.23 to 0.83$)$ & $0.57(0.48$ to 0.65$)$ & 1.27 (0.72 to 2.24$)$ & $0.80(0.41$ to 1.55$)$ \\
\hline & & & & Perinatal death & $0.82(0.48$ to 0.98$)$ & 0.59 (0.51 to 0.67$)$ & 2.00 (1.42 to 2.81$)$ & 0.31 (0.09 to 1.09$)$ \\
\hline & & & & Stillbirth & 0.71 (0.29 to 0.96$)$ & 0.57 (0.49 to 0.66$)$ & 1.68 (1.01 to 2.78 ) & 0.50 (0.15 to 1.62$)$ \\
\hline $\begin{array}{l}\text { Nisell } \\
(2006)\end{array}$ & Hypertension & 54 & $\geq 27 \mathrm{mg} / \mathrm{mL}$ & $\begin{array}{c}24 \text { hour urine }(>0.3 \\
\text { g/24 hours) }\end{array}$ & 0.95 (0.85 to 0.99$)$ & $1.00(0.82$ to 1.00$)$ & $\begin{array}{c}37.54(2.43 \text { to } \\
580.14)\end{array}$ & $0.06(0.02$ to 0.17$)$ \\
\hline \multirow[t]{3}{*}{$\begin{array}{l}\text { Waugh } \\
(2005)\end{array}$} & \multirow[t]{3}{*}{$\begin{array}{l}\text { Hypertension } \\
\text { after } 20 \text { weeks }\end{array}$} & \multirow[t]{3}{*}{171} & $\begin{array}{c}\text { Visual } \\
\text { microalbumin } \\
\text { dipstick } \geq 3.4 \\
\mathrm{mg} / \mathrm{mmol} \\
\end{array}$ & \multirow[t]{3}{*}{$\begin{array}{c}24 \text { hour urine }(>0.3 \\
g / 24 \text { hours })\end{array}$} & $0.49(0.38$ to 0.61$)$ & $0.83(0.74$ to 0.90$)$ & 2.90 (1.76 to 4.78$)$ & 0.61 (0.48 to 0.78$)$ \\
\hline & & & $\begin{array}{c}\text { Automated } \\
\text { microalbumin } \\
\text { dipstick } \geq 3.4 \\
\mathrm{mg} / \mathrm{mmol}\end{array}$ & & 0.58 (0.47 to 0.70$)$ & 0.83 (0.74 to 0.90$)$ & $3.43(2.11$ to 5.57$)$ & 0.50 (0.38 to 0.66$)$ \\
\hline & & & $\begin{array}{c}\text { DCA } 2000 \\
\text { quantitative } \geq 2 \\
\mathrm{mg} / \mathrm{mmol}\end{array}$ & & 0.94 (0.86 to 0.98$)$ & 0.94 (0.87 to 0.98$)$ & $\begin{array}{c}14.65 \text { (6.74 to } \\
31.84)\end{array}$ & 0.07 (0.03 to 0.16$)$ \\
\hline
\end{tabular}

HDU=high dependency unit. 


\section{Figures}

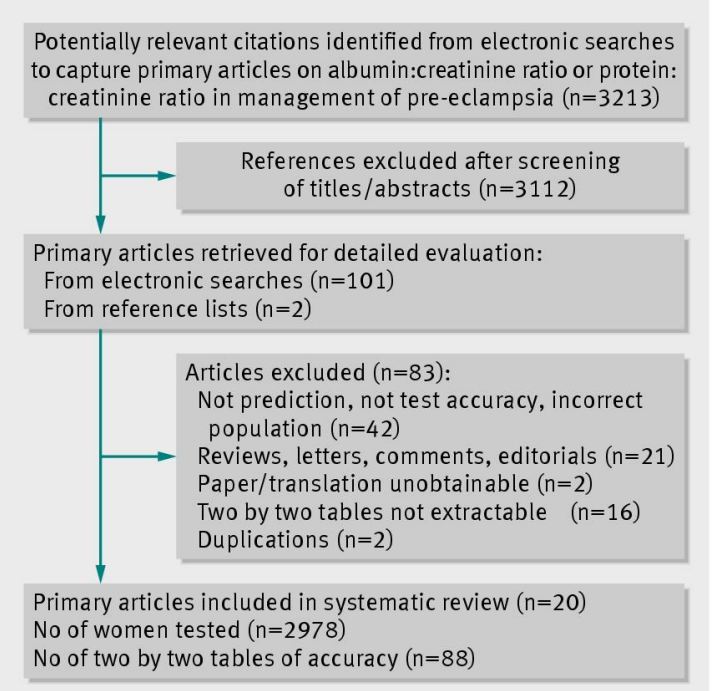

Fig 1 Process from initial search to final inclusion for albumin to creatinine ratio or protein to creatinine ratio in management of pre-eclampsia (up to January 2011)

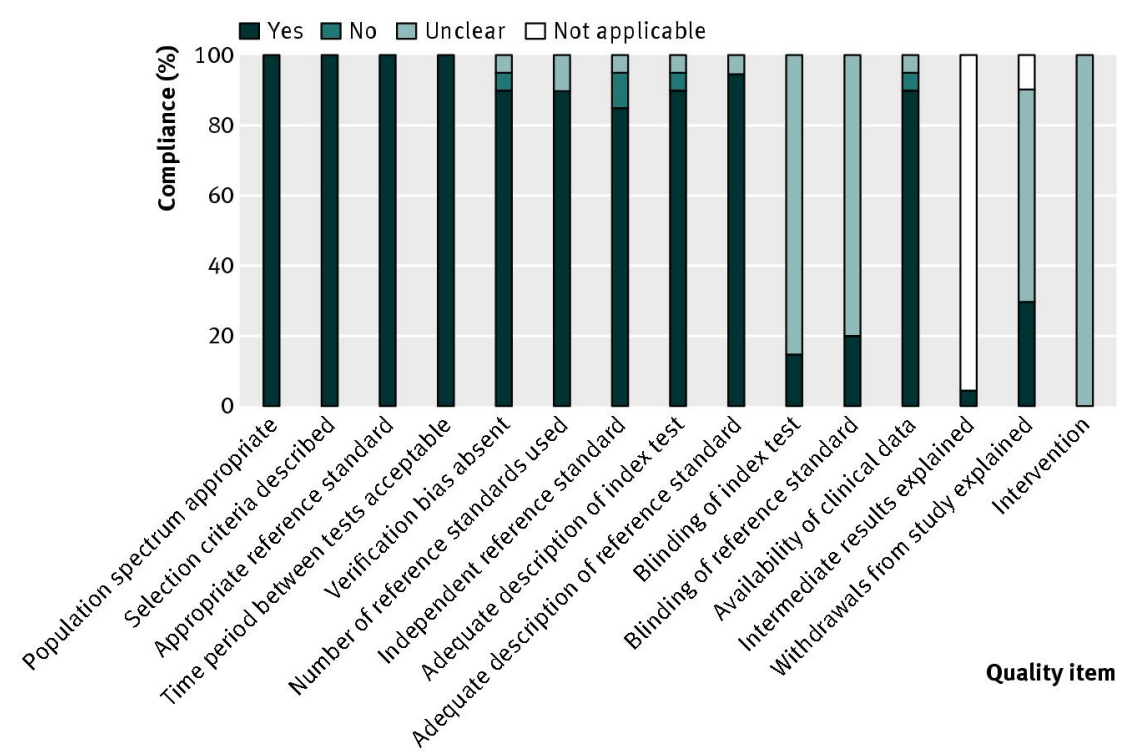

Fig 2 Bar chart showing quality assessment using QUADAS criteria of included papers in systematic review of albumin to creatinine ratio and protein to creatinine ratio in management of pre-eclampsia. Availability of clinical data refers to "Were the same clinical data available when test results were interpreted as would be available when the test is used in practice?" 


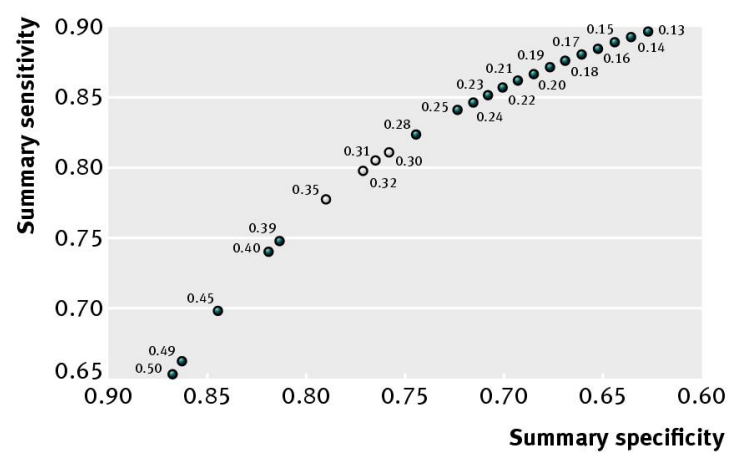

Fig 3 Summary receiver operating characteristics curve for constrained estimates of sensitivity and specificity for protein to creatinine ratio. Open circles indicate most promising thresholds for use, as they optimise both sensitivity and specificity (and thus give largest rectangular area below paired point to right) 